http://dx.doi.org/10.18675/1981-8106.vol25.n48.p54-66

\title{
Relações entre Autonomia e Projeto Político-Pedagógico de Escolas Públicas
}

\author{
Relations between Autonomy and Political-Pedagogic Project of Public \\ Schools
}

\section{Relaciones entre Autonomía y Proyecto Político-Pedagógico de Escuelas Públicas}

\author{
Francielle Camargo ' \\ Simone de Fátima Flach" \\ ' Universidade Estadual de Ponta Grossa (UEPG), Paraná - Brasil. E-mail: fcamaargo@hotmail.com \\ "Universidade Estadual de Ponta Grossa (UEPG), Paraná - Brasil. E-mail: eflach@uol.com.br
}

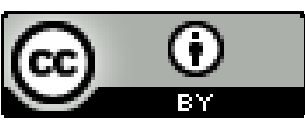

Educação: teoria e prática, Rio Claro, SP, Brasil - eISSN: 1981-8106

Está licenciada sob Licença Creative Common

\section{Resumo}

Derivado de pesquisa mais ampla, este artigo procura refletir sobre o desenvolvimento da autonomia de escolas públicas através do Projeto Político-pedagógico. A partir da análise de dados colhidos em pesquisa de natureza qualitativa, o texto apresenta como acontecem e são previstas as interações entre escola e comunidade nos âmbitos social, governamental e escolar e suas implicações para a organização do Projeto Político-pedagógico em escolas públicas e sua relação com o desenvolvimento da autonomia. As análises indicam que para o trabalho pedagógico e escolar atender as necessidades educativas da comunidade precisa pautar-se em um Projeto político-pedagógico socialmente referenciado. E, ainda, que o desenvolvimento da autonomia da escola via projeto político-pedagógico situa-se em espaço contraditório, onde avanços e recuos são presentes e se fazem necessários. Além dessas questões, conclui-se que há, ainda, no meio educacional, muita dificuldade em entender como o Projeto Políticopedagógico pode auxiliar na conquista de uma escola democrática e autônoma. 
Palavras-chave: Autonomia Escolar; Projeto Político-pedagógico; Desenvolvimento Institucional.

\begin{abstract}
Derived from broader research, this paper discuss the development of autonomous public schools through the political-pedagogic project. From the analysis of data collected in qualitative research, the text presents as they occur and are predicted interactions between school and community in the social, government and its implications for the organization of the political-pedagogic project of public schools and its relationship to the development of autonomy. The analyzes indicate that for the pedagogical work and school meet the educational needs of the community must be based on a political-pedagogic project socially referenced. And also that the development of school autonomy through political-pedagogic project is located in contradictory space where advances and retreats are present and are needed. In addition to these questions it is concluded that there is still, in the educational environment, much difficulty in understanding how the political-pedagogic project can assist in achieving a democratic school and autonomous.
\end{abstract}

Keywords: School Autonomy; Political-pedagogic Project; Institutional development.

\title{
Resumen
}

Derivado de una investigación más amplia, este artículo procura reflexionar sobre el desarrollo de la autonomía de escuelas públicas a través del Proyecto Político-pedagógico. A partir del análisis de datos recogidos en una investigación de naturaleza cualitativa, el texto presenta cómo acontecen y se prevén las interacciones entre escuela y comunidad en los ámbitos social, gubernamental y escolar, y sus implicaciones para la organización del Proyecto Político-pedagógico en escuelas públicas y su relación con el desarrollo de la autonomía. Los análisis indican que, para que el trabajo pedagógico y escolar atienda las necesidades educativas de la comunidad, estas precisan pautarse en un Proyecto políticopedagógico socialmente referenciado. E, incluso, que el desarrollo de la autonomía de la escuela vía proyecto político-pedagógico se sitúa en un espacio contradictorio, donde avances y retrocesos están presentes y se hacen necesarios. Además de estas cuestiones, se concluye que aún hay, en el medio educacional, mucha dificultad en entender cómo el Proyecto Político-pedagógico puede auxiliar en la conquista de una escuela democrática y autónoma.

Palabras clave: Autonomía Escolar; Proyecto Político-pedagógico; Desarrollo Institucional. 


\section{Introdução}

O presente texto pretende relatar dados de Pesquisa ${ }^{1}$, cuja temática centra-se no desenvolvimento da autonomia de escolas públicas em um município do estado do Paraná, através do Projeto Político-pedagógico. A pesquisa busca, dentre outros objetivos: analisar o desenvolvimento de escolas públicas, através das ações de construção, efetivação e avaliação de seus projetos político-pedagógicos; contribuir na compreensão dos estudantes de cursos de graduação em diversas licenciaturas, docentes e gestores escolares sobre os condicionantes internos e externos que influenciam na construção da autonomia pedagógica das escolas; e, ainda, realizar levantamento bibliográfico sobre a importância do projeto político-pedagógico para a efetivação da função social das escolas no atual momento histórico.

A pesquisa que deu origem ao presente texto foi dividida em duas etapas. Durante a primeira etapa de desenvolvimento foi realizado levantamento de estudos de caráter científico (existência de teses e dissertações), relativos ao processo de autonomia de escolas e sua relação com a existência de um projeto político-pedagógico baseado na realidade educacional e social onde as escolas estão inseridas. O levantamento bibliográfico centrou-se em temáticas envolvidas na discussão proposta, tais como: autonomia, projeto político-pedagógico, desenvolvimento institucional e os encaminhamentos político-educacionais em curso. Destaca-se que foram mapeados, no Banco de Dados da Capes, relativos ao período de 2006 a 2010, 612 documentos, sendo 512 dissertações e 100 teses, dos quais 401 foram excluídos por insuficiência de dados, dados conflitantes ou impertinência temática. Os demais documentos foram incorporados ao estudo e subsidiam a análise sobre o desenvolvimento das escolas públicas, através das ações de elaboração, efetivação e avaliação de seus projetos políticopedagógicos. A partir desse levantamento, foi possível identificar a necessidade de análise sobre a autonomia da escola, temática que tem sido objeto de estudos e tem se incorporado às discussões.

$\mathrm{Na}$ segunda etapa e a partir do estudo relativo ao acervo sobre a temática, ocorreu a análise de estratégias utilizadas pelas escolas para um trabalho efetivo via projeto políticopedagógico, desde a sua elaboração, efetivação e consequente avaliação. Para tanto, se tornou necessário o acompanhamento de experiências in loco com o objetivo de confrontar os estudos realizados com o cotidiano escolar, contribuindo para a construção de referenciais teórico-práticos sobre o desenvolvimento da autonomia via projeto político-pedagógico em escolas públicas.

Procurando evidenciar os resultados da pesquisa realizada, o presente artigo caracteriza-se como um ensaio preliminar, apontando principais autores que subsidiam as análises empreendidas e os caminhos percorridos na construção teórica da pesquisa.

\footnotetext{
1 Pesquisa de Iniciação Científica intitulada O Projeto político-pedagógico como possibilidade de desenvolvimento da autonomia das escolas públicas, vinculada ao Projeto de Pesquisa Escolas Municipais em Ponta Grossa: determinantes na criação, existência político-pedagógica e cessação de atividades escolares, em processo de desenvolvimento junto à Universidade Estadual de Ponta Grossa - UEPG.
} 


\title{
2 Para Início de Conversa...
}

Para envidar a discussão proposta, faz-se necessário esclarecer como a possibilidade de desenvolvimento da autonomia através do projeto político-pedagógico vem sendo entendida no meio educacional brasileiro. Nesse sentido, procuramos trazer algumas discussões acerca desse importante documento e sua relação com o desenvolvimento da autonomia entre os pesquisadores da área.

Preliminarmente, é preciso esclarecer que o termo Projeto Político-pedagógico não é unânime entre autores, pesquisadores e gestores educacionais, o que não modifica a sua finalidade. Comumente, esse documento recebe diferentes denominações, tais como Proposta Pedagógica, Projeto Pedagógico, Projeto Educativo e/ou Projeto de Escola. Até mesmo a Lei de Diretrizes e Bases da Educação Nacional - Lei 9394/96, utiliza termos diferentes para referir-se ao mesmo objeto (em seus artigos 12 e 13 recebe a denominação de Proposta Pedagógica e no artigo 14 a denominação Projeto Pedagógico refere-se ao mesmo documento). Defendemos a denominação de Projeto Político-pedagógico por entendermos que se trata de um documento ao mesmo tempo político e pedagógico (BRASIL, 1996).

A esse respeito, se mostram importantes as reflexões feitas por Gandin e Gandin (2011), quando esclarecem diferenças substanciais relativas às denominações Projeto Pedagógico e Projeto Político-pedagógico:

\begin{abstract}
Atualmente, os estudos realizam-se sobre o que se denomina "Projeto Pedagógico" ou, com mais força, "Projeto Político-pedagógico". Mais do que isto: a corrente de planejamento que vai ficando conhecida como "planejamento participativo" e que busca fazer, para as instituições cujo primeiro fim é o de contribuir para a construção da sociedade (caso das escolas), aquilo que o "planejamento estratégico" e o "gerenciamento da qualidade total" fazem para as que têm como tarefa primeira o lucro e a sobrevivência, esta corrente do planejamento propõe o projeto político-pedagógico como um dos momentos do planejamento, ao qual deve juntar-se um diagnóstico para julgar a prática e uma proposta concreta, para um tempo, de nova prática (GANDIN; GANDIN, 2011, p. 15-16).
\end{abstract}

Nesse sentido, adotamos e defendemos o termo Projeto Político-pedagógico em razão de que o seu significado expressa um posicionamento político e ideológico radical, comprometido com transformação da realidade. Essa perspectiva de entendimento do termo demonstra um posicionamento que situa e direciona o planejamento escolar de forma consciente sobre a realidade e busca uma prática democrática que abranja e comprometa todos os envolvidos no planejamento educativo. Assim, o político e 
pedagógico se tornam indissociáveis para a compreensão do significado e da importância desse documento no contexto escolar.

No mesmo sentido, Pinto (2011) também defende o emprego do termo, no seguinte sentido:

Político porque busca um rumo, uma direção intimamente articulada ao seu compromisso sociopolítico: os interesses reais e coletivos da população majoritária. [...]. Pedagógico porque sua efetivação depende do encaminhamento das ações educativas que permitam atingir suas intencionalidades (PINTO, 2011, p.148).

Assim, consideramos que o Projeto político-pedagógico se constitui em documento imprescindível para direcionar, política e pedagogicamente, o trabalho a ser desenvolvido pelos profissionais da escola.

A direção política do trabalho escolar ocorre através da tomada consciente e explícita de posição em relação aos educandos e comunidade circundante à escola, através de ações nunca neutras, mas carregadas de intencionalidade. Nesse sentido, as ações empreendidas pelo coletivo escolar extrapolam os muros, atingindo as relações e vida social.

A direção pedagógica ocorre através de ações educativas que visam realizar a função precípua da escola, esclarecendo por que e como ensinar. A orientação das ações educativas a serem implementadas dependem das opções políticas e pedagógicas assumidas coletivamente. Essas opções dão eficiência e eficácia ao trabalho educativo, de forma a consolidar os atos de ensinar e aprender.

Portanto, conforme nos esclarece Libâneo, Oliveira e Toschi (2007), esse documento tem a função de formular metas, prever ações e instituir os procedimentos necessários para a ação educativa. Nesse sentido, o Projeto Político-pedagógico torna-se essencial para o trabalho a ser desenvolvido pela escola, sendo que, sem ele, as ações se tornam aleatórias, correndo o risco de serem inócuas. Defende-se, portanto, que o fazer pedagógico e educativo se torna significativo e com maior possibilidade de se efetivar de maneira satisfatória quando o Projeto político-pedagógico é o eixo norteador das ações.

Segundo Faria e Salles (2007) é por meio do Projeto Político-pedagógico que a escola define sua identidade e concretiza sua intenção para orientar a prática pedagógica. Nessa perspectiva, o Projeto político-pedagógico se traduz em linha mestra para todo o trabalho escolar, da qual derivam todas as ações desenvolvidas em prol dos objetivos estabelecidos, os quais convergem para a realidade e comunidade atendida. É por isso que cada escola precisa definir o seu Projeto Político-pedagógico, constituindo-o em documento único para uma comunidade escolar específica, sem perder de vista a totalidade da sociedade da qual faz parte, instrumentando os sujeitos para agirem de forma efetiva nessa sociedade, mantendo-a ou transformando-a. As escolhas políticas e pedagógicas da escola se materializam nas ações 
educativas, mas seus resultados se efetivarão no âmbito da prática social, através de ações, atitudes e decisões que os sujeitos assumem perante a sociedade onde vivem.

É por tudo isso que entender como o Projeto Político-pedagógico colabora na constituição de sujeitos autônomos, e como a autonomia da escola se constitui através dele, consiste, ainda, num desafio da pesquisa relatada e dos pesquisadores da área em geral.

\section{Interação entre Escola e Comunidade: ocorrências nos âmbitos social, escolar e governamental}

As tentativas e lutas pela interação da escola com a comunidade não são recentes, mas têm se pautado, na maioria das vezes, pelo insucesso, mesmo após a reabertura política brasileira e as inúmeras iniciativas de implementação de maior participação no âmbito escolar.

Ao analisarmos a realidade político-educacional brasileira podemos afirmar que, historicamente, a educação para a população sempre foi considerada favor político e não direito adquirido e assegurado legalmente. Nessa perspectiva, convém esclarecer:

\footnotetext{
Um direito assegurado nas normas jurídicas não equivale à sua garantia, visto situar-se no campo da previsão. É somente na materialidade das relações humanas que as normas serão ou não efetivamente garantidas. A garantia de determinada previsão legal depende, necessariamente, de ações específicas do ente responsável que cumpre a obrigação assegurada formalmente fazendo com que seja garantida na realidade concreta. A previsão de determinado direito nas normas escritas por si só não possibilita que os indivíduos usufruam desse direito, pois somente quando tal previsão passa a ser conhecida é que se cria a possibilidade de sua reivindicação. Caso contrário, um direito assegurado na letra da lei não passará de simples previsão, de simples intenção, sem garantia de cumprimento da obrigação (FLACH, 2011, p.245).
}

Tomando como referência a citação acima, pensar em maior participação da comunidade nos espaços escolares, mesmo que esta seja prevista em lei, é deveras complicado, pois tal pensamento traz em seu bojo uma série de questões de ordem histórica e social. É preciso considerar que, historicamente, na realidade brasileira houve poucos espaços de participação popular nos encaminhamentos de decisões, sejam de ordem geral ou específica, cabendo as decisões a determinados grupos ligados à classe dominante. Isso ocorreu devido à organização social que reforça a divisão em classes. Nessa lógica, a classe que detêm a hegemonia mantém o comando, enquanto à classe subalterna cabe a subordinação e anuência das decisões e encaminhamentos previamente estabelecidos.

Em contrapartida, a realidade é contraditória sendo necessário entendê-la em sua totalidade. Para além do caráter de favor político, a participação precisa ser entendida como avanço na conquista e fruição de direitos pela população brasileira. Por isso, as iniciativas de 
interação entre escola e comunidade assumem um papel imprescindível na reflexão que se pretende sobre o projeto político-pedagógico da escola atual.

A partir de pesquisa de iniciação científica intitulada Projeto Político-pedagógico como possibilidade de desenvolvimento da autonomia das escolas públicas, onde se buscou realizar levantamento de pesquisas sobre a temática ${ }^{2}$, podemos considerar que as iniciativas de promover maior interação entre escola e comunidade ocorrem em três âmbitos: social, escolar e governamental. O primeiro é aquele localizado no espaço da prática social, onde os movimentos sociais reivindicam maior participação nos espaços educacionais, principalmente através de maior acesso à educação, ou seja, na reivindicação do direito à educação e todas as consequências dele derivadas. O segundo se situa no espaço interno das instituições educacionais, se materializando através de ações dos profissionais da educação que buscam relacionar as práticas educativas com as práticas e necessidades presentes e futuras da sociedade. $\mathrm{O}$ terceiro se traduz na criação de normas específicas que assegurem ao âmbito social e escolar reivindicar espaços e criar estratégias de ação.

A interação da escola com a comunidade no âmbito social ocorre no seio dos movimentos sociais, a partir de reivindicações dos sujeitos para maior participação no contexto escolar. Essas reivindicações ocorreram, de forma direta ou indireta, ao longo da história educacional brasileira, seja através da possibilidade de participação financeira com a criação das Associações de Pais e Mestres ou mesmo através dos atuais Conselhos Escolares ou Conselhos de Escola, que trazem em seu bojo o gérmen da participação e discussão coletiva. No entanto, a interação muitas vezes reivindicada pela sociedade se transformou, a partir de 1999, com o lançamento do Projeto Amigos da Escola, capitaneado pela Rede Globo, quando a participação da sociedade assumiu caráter de voluntariado, desvalorizando os profissionais da educação. Essa forma de interação entre escola e comunidade substituiu ou contribuiu para a substituição da possibilidade de desenvolvimento de autonomia conjunta entre os sujeitos que compõe a comunidade escolar, pois sua centralidade se situa na inserção de voluntários para a execução de atividades cotidianas da escola, sem a garantia de discussão sobre o projeto pedagógico e os interesses educacionais e sociais em disputa. A participação na tomada de decisão sobre os encaminhamentos político-educacionais e suas repercussões na realidade escolar fica obscurecida pela prestação de serviços prestada por voluntários. Nesse cenário, portanto, o projeto político-pedagógico se torna secundário e o desenvolvimento da autonomia se fragiliza.

A interação no âmbito escolar tem se evidenciado nas ações e estratégias utilizadas pela escola, em especial pela equipe gestora das escolas, com o intuito de promover a participação nas decisões necessárias para o funcionamento da escola. Tais ações ocorrem a partir das orientações legais e normativas e, ainda, por iniciativa interna dos profissionais em prol da oferta de uma educação de maior qualidade. Nesse espaço se situam ações como: elaboração coletiva de projetos político-pedagógicos, bem como acompanhamento na sua implantação e avaliação, reencaminhando ações necessárias para o atendimento dos objetivos

\footnotetext{
2 A pesquisa mapeou, no Banco de Teses da Capes, 181 produções de mestrado e 30 de doutorado que apresentam relação direta com o projeto político-pedagógico e autonomia de escolas.
} 
previstos; acompanhamento da utilização dos recursos públicos recebidos, através de tomada de decisões sobre o seu uso e prestação de contas, através de participação de Associação de Pais e Mestres, Conselhos Escolares ou outros órgãos equivalentes; acompanhamento do desempenho escolar dos alunos através da realização de Conselhos Escolares específicos para esse fim ou mesmo Conselhos de Classe com a participação da comunidade (conforme previsão no projeto político-pedagógico e regimento escolar), dentre outras.

A criação de normas específicas, que orientem o processo de interação entre escola e comunidade, ocorre em âmbito governamental, através de leis, regulamentos oriundos do poder legislativo e executivo e, ainda, dos órgãos normativos do Sistema Educacional. Tais orientações administrativas e legais colaboram para a organização interna da escola em busca de maior interação com a comunidade e podem ser identificados nos princípios previstos na Constituição Federal, dispositivos específicos na Lei de Diretrizes e Bases da Educação Nacional (Lei $n^{\circ}$ 9394/96), Estatuto da Criança e do Adolescente (Lei $n^{\circ}$ 8069/90), Resoluções dos órgãos normativos (Conselhos Nacional, Estaduais e Municipais de Educação) e, ainda, orientações os órgãos executivos (Secretarias Estaduais e Municipais de Educação).

As iniciativas e previsões para promover maior interação da escola com a comunidade, conforme ocorrem nos âmbitos sociais, escolar e governamental contribuem para o desenvolvimento da autonomia individual e coletiva dos sujeitos envolvidos no processo educativo. É nesse contexto que o Projeto político-pedagógico da escola assume centralidade, pois é através dele que a interação se evidencia e se torna fato no cotidiano escolar.

\section{Relações entre Projeto Político-Pedagógico e Autonomia Escolar}

Ao assumir a centralidade na discussão sobre os caminhos percorridos e a percorrer pela escola, o Projeto Político-pedagógico evidencia sua importância para o fazer pedagógico. Segundo Faria e Salles (2007), é por meio do Projeto Político-pedagógico que a escola define sua identidade, concretizando sua intenção para orientar a prática pedagógica. É nesse sentido que a elaboração do Projeto Político-pedagógico é um processo único e, ao mesmo tempo, coletivo. Único, por ser próprio de cada escola, considerando sua historicidade, seus avanços e as suas dificuldades. Coletivo, por se traduzir na intenção coletiva de ação educativa em prol de objetivos comuns, evidenciando a intenção educacional. Desse modo, Veiga (1995) nos esclarece que

[...] o projeto político-pedagógico vai além de um simples agrupamento de planos de ensino e de atividades diversas. O projeto não é algo que é construído e em seguida arquivado ou encaminhado às autoridades educacionais como prova do cumprimento de tarefas burocráticas. Ele é construído e vivenciado em todos os momentos, por todos os envolvidos com o processo educativo da escola (VEIGA, 1995, p.14). 
Nessa perspectiva, o Projeto Político-pedagógico é um documento muito íntimo e individual da escola, pois é a sua identidade e o seu guia para dar sentido aos momentos vivenciados naquela instituição, devendo se traduzir em diretrizes para o trabalho pedagógico, superando o entendimento de um simples documento burocrático.

Por isso, é um documento de busca pela autonomia da escola, pois quando é elaborado a partir da realidade, a escola consegue executá-lo e avaliá-lo coletivamente, refletindo constantemente sobre o seu papel na sociedade. A ação coletiva dos sujeitos envolvidos funciona como uma mola propulsora para o desenvolvimento da autonomia, pois fortalece as ações e as torna mais pontuais conforme as necessidades evidenciadas. Dessa forma, Veiga (1995), afirma que

A ideia de autonomia está ligada à concepção emancipadora da educação.
Para ser autônoma, a escola não pode depender dos órgãos centrais e
intermediários que definem a política da qual ela não passa de executora. Ela
concebe seu projeto político-pedagógico e tem autonomia para executá-lo e
avaliá-lo ao assumir uma nova atitude de liderança, no sentido de refletir
sobre as finalidades sociopolíticas e culturais da escola (VEIGA, 1995,
p.24).

No entanto, o alcance da autonomia pela escola é questão contraditória, pois não ocorre de forma imediata, mas a partir de um confronto de forças, muitas vezes antagônicas. Esse processo é, muitas vezes, árduo e demorado.

A autonomia é um campo de forças, onde confrontam e equilibram diferentes detentores de influencia (externa e interna) dos quais se destacam: o governo, a administração, professores, alunos, pais e outros membros da sociedade local (BARROSO, 1998, p.17).

O desenvolvimento da autonomia pela escola traz à tona a vontade individual e coletiva de ousar, de percorrer caminhos ainda desconhecidos, e a ousadia de enfrentar desafios e procurar resolver problemas que eventualmente se mostrem presentes. Essa escolha nem sempre é fácil e rápida. Nesse sentido, as palavras de Malheiro (2005) nos ajudam a entender a importância da autonomia no contexto escolar:

Sua eficácia depende muito da ousadia de cada escola em experimentar o novo. Mas, para isso, é preciso percorrer um longo caminho de construção de confiança na escola, na capacidade de ela resolver seus problemas e dificuldades e de achar os melhores caminhos para sua clientela (MALHEIRO, 2005, p. 86).

Assim sendo, para que o Projeto Político-pedagógico seja um instrumento de autonomia, precisa ser construído com a participação de todos os profissionais da escola e da comunidade, tornando-os corresponsáveis e comprometidos com a educação dos alunos. Dessa forma, todos se tornam sujeitos desde a elaboração do Projeto Político-pedagógico, se comprometendo com a sua implementação e posterior avaliação. Nessa direção,

[...] a participação é o principal meio de assegurar a gestão democrática, possibilitando o envolvimento de todos os integrantes da escola no processo 
de tomada de decisões e no funcionamento da organização escolar. A participação proporciona melhor conhecimento dos objetivos e das metas, de sua estrutura organizacional e de sua dinâmica, de suas relações com a comunidade e propicia um clima de trabalho favorável a maior proximidade entre professores, alunos e pais (LIBÂNEO; OLIVEIRA; TOSCHI, 2007, p.328).

No entanto, fazer com que os profissionais da escola e comunidade externa participem da elaboração do Projeto Político-pedagógico ainda é um grande desafio a ser enfrentado. Segundo Veiga:

Para que a construção do projeto politico-pedagógico seja possível não é necessário convencer os professores, a equipe escolar e os funcionários a trabalhar mais, ou mobilizá-los de forma espontânea, mas propiciar situações que lhes permitam aprender a pensar e a realizar o fazer pedagógico de forma coerente (VEIGA, 1995, p. 15).

Segundo Veiga (2002), a gestão democrática, construída com a participação de todos no processo de tomada de decisões, rompe com as divisões fragmentadas de trabalho e com as diferenças e formas de controle hierárquico. Dessa forma, há uma transparência nas tomadas de decisões e comprometimento com a execução das propostas. Assim,

O projeto politico-pedagógico, ao se constituir em processo democrático de decisões, preocupa-se em instaurar uma forma de organização do trabalho pedagógico que supere os conflitos, buscar eliminar as relações competitivas, corporativas e autoritárias, rompendo com a rotina do mando impessoal e racionalizado da burocracia que permeia as relações no interior da escola, diminuindo os efeitos fragmentários da divisão do trabalho que reforça as diferenças e hierarquiza os poderes de decisão ( VEIGA, 1995, p. $15)$.

Dessas reflexões é possível afirmar que a elaboração do Projeto Político-pedagógico é um desafio para todos os envolvidos no processo educacional, pois exige uma participação crítica em busca da formação de um cidadão para determinada sociedade. Portanto, defendemos a ideia de que os envolvidos precisam ter clara qual seja a concepção que fundamenta suas ações, e de que forma essa concepção fornece os subsídios necessários para a resolução dos problemas da educação e daquela escola. Em nosso entendimento, essa concepção precisa ter o compromisso com a população que necessita da escola e com a luta por uma sociedade não excludente.

A concepção (de homem, mundo, sociedade), os princípios e as finalidades prescritas no Projeto Político-pedagógico orientam as práticas cotidianas em busca de uma educação de qualidade. Por isso, o Projeto político-pedagógico não é neutro, mas eivado de intencionalidade e em busca de fins explícitos. A clareza dos fundamentos que orientam a prática também é uma componente essencial para se entender como se constitui a autonomia da escola. A comunidade, externa e interna, precisa definir as finalidades da escola e, para tal, 
qual o tipo de cidadão e de sociedade estão formando. Ter consciência disso faz toda a diferença.

Assim, para se chegar ao fim é necessário definir o meio. Na elaboração do Projeto Político-pedagógico também é necessária a distinção clara entre meios e fins. A autonomia também se evidencia na capacidade da escola em conseguir definir as formas como irá atingir os objetivos e finalidades previstos. Nessa perspectiva, é imprescindível que os elementos que compõe o Projeto Político-pedagógico sejam articulados entre si, e não prescritos de forma isolada. Ou seja, para atingir determinados objetivos, a definição dos meios necessários é imprescindível, pois, caso contrário, se traçarão objetivos e metas para os quais não serão estabelecidas as estratégias necessárias.

Entrelaçar, de forma coerente, realidade da qual se parte, concepções que nortearão as ações, objetivos e metas, estratégias possíveis, prazos e formas de avaliação não é tarefa simples. Mas é através desse entrelaçamento, o qual só se efetiva de forma coletiva, que a escola constrói a própria autonomia. Fica claro, portanto, que o Projeto Político-pedagógico caracteriza-se como um instrumento de autonomia da escola, pois através dele a instituição ganha identidade própria.

\section{Importância do Projeto Político-Pedagógico para a Autonomia das Escolas Públicas}

Os estudos realizados demonstram que o desenvolvimento da autonomia tem relação direta com o projeto político-pedagógico das escolas públicas e as estratégias utilizadas nos contextos social, governamental e escolar para sua efetivação. Igualmente, a questão se insere no debate sobre a gestão democrática e como esta vem se desenvolvendo no interior das escolas a partir dos encaminhamentos políticos e educacionais em curso na atualidade.

É preciso considerar que em comunidades pobres e carentes de recursos, onde os direitos da população são muitas vezes negligenciados, a escola exerce papel fundamental na construção de estratégias para o desenvolvimento da cidadania da população circundante. Nesse sentido, o estudo sobre o desenvolvimento da autonomia da escola via projeto políticopedagógico extrapola os muros escolares e atinge a população, fazendo com que a escola exerça uma função social importante: a de vivenciar a cidadania com a população que dela necessita. Sob esse aspecto, a cidadania deixa de ser apenas previsão para se tornar ação.

O envolvimento coletivo com os rumos da escola e o compromisso com os resultados obtidos têm demonstrado como o processo de constituição da autonomia dos sujeitos está imbricado com as ações da escola e vice-versa. Entretanto, o envolvimento coletivo interno e externo com o projeto político-pedagógico não é tarefa que ocorra de forma imediata, sendo necessário um processo de conquista, avanços e recuos individuais e coletivos, visando à construção de caminhos comuns, onde a escola se insere na comunidade e a comunidade se insere na escola, de forma a tornarem-se um todo, senão único, mas com objetivos claros e 
compartilhados. Para isso acontecer torna-se necessário questionar, desafiar a realidade existente e as práticas já consolidadas no cotidiano escolar para construir outras práticas, mais democráticas, mais voltadas para as necessidades, interesses e possibilidades da população que necessita da escola pública.

Quando as decisões coletivas legitimam e sustentam as ações a serem realizadas na execução do Projeto político-pedagógico, a escola assume atitude de liderança no cumprimento de suas finalidades sociais, políticas e culturais na sociedade. Nesse sentido, a escola cumpre seu papel de forma ampla e irrestrita.

Embora a pesquisa não esteja ainda concluída, é possível apontar sua importância para o contexto acadêmico, visto que traz à tona a discussão sobre a importância da escola pública; a emergência de um projeto político-pedagógico verdadeiramente voltado para as necessidades da comunidade escolar; além da importância do envolvimento coletivo em busca de objetivos claros e comuns. Também, a pesquisa tem evidenciado: as dificuldades que a escola enfrenta para mobilizar a comunidade na atual sociedade capitalista, onde os objetivos individuais se sobrepõem aos coletivos $^{3}$; a fragilidade da organização escolar em busca de uma escola de qualidade socialmente referenciada; alguns encaminhamentos políticoeducacionais que impedem um trabalho escolar mais autônomo, dentre outros entraves.

Ao elencarmos esses obstáculos e desafios, fica explícita a importância de dar ênfase a essas questões, as quais estão obscurecidas no emaranhado do trabalho pedagógico e escolar. Essa tarefa é deveras desafiadora...

\section{Para Concluir...}

As relações existentes entre autonomia e projeto político-pedagógico de escolas públicas têm-se mostrado contraditórias, pois, ao mesmo tempo em que se mostram como possibilidades de avanço, também evidenciam recuos. Os avanços se mostram quando as ações são efetivadas em busca do desenvolvimento da autonomia individual e coletiva da comunidade interna e externa à escola. No entanto, os recuos estão presentes e, muitas vezes, se fazem necessários para atender encaminhamentos de órgãos superiores ou mesmo os interesses de determinado grupo que, por ora, está no comando das ações, seja em nível escolar ou de sistema educacional.

Para que a organização escolar atenda às necessidades educativas da comunidade que necessita da escola pública, o trabalho com o Projeto Político-pedagógico torna-se imprescindível. Todavia, há, ainda, muita dificuldade em entender como o Projeto Políticopedagógico pode auxiliar na conquista de uma escola democrática e autônoma. Esse é um desafio a ser enfrentado.

\footnotetext{
3 A mobilização da comunidade interna e externa para a elaboração, implementação e avaliação do Projeto Político-pedagógico é temática que vem sendo objeto de outro estudo.
} 


\section{Referências}

BARROSO, J. O reforço da autonomia das escolas e a flexibilização da gestão escolar em Portugal. In: FERREIRA, N. S.C. (Org.). Gestão democrática da educação: atuais tendências, novos desafios. São Paulo: Cortez, 1998. p. 11-32.

BRASIL. Casa Civil. Lei 9394, de 20 de dezembro de 1996. Estabelece as Diretrizes e Bases da Educação Nacional. Disponível em:

<http://www.planalto.gov.br/ccivil_03/leis/19394.htm>. Acesso em: 19 mar. 2015.

FLACH, S. F. Direito à educação e ampliação da escolaridade obrigatória em Ponta

Grossa (2001 2008). 2011. 316 f. Tese (Doutorado em Educação) - Universidade Federal de São Carlos, São Carlos, 2011.

FARIA, V.; SALLES, F. O currículo como um dos elementos da proposta pedagógica. In: Currículo na educação infantil: diálogo com os demais elementos da proposta pedagógica. São Paulo: Scipione, 2007. p. 20-42.

GANDIN, D; GANDIN, L. A. Temas para um projeto político-pedagógico. 12 ed. Petrópolis: Vozes, 2011.

LIBÂNEO, J. C.; OLIVEIRA, J. F. de; TOSCHI, M. S. O sistema de organização e de gestão da escola: teoria e prática. In: . Educação Escolar: políticas, estrutura e organização. São Paulo: Cortez, 2007.p. 315-351.

MALHEIRO, J. Projeto Político-pedagógico: Utopia ou Realidade? Ensaio: aval. pol. publ. Educ., Rio de janeiro, v.13, n.46, p.79-104, jan./mar. 2005.

PINTO, U. A. Pedagogia escolar: coordenação pedagógica e gestão educacional. São Paulo: Cortez, 2011.

VEIGA, I. P. A. Projeto político-pedagógico da escola: uma construção coletiva. In: VEIGA, I. P. A. (org.) Projeto político-pedagógico da escola: uma construção possível. 10 ed. Campinas: Papirus, 1995.

VEIGA, I. P. A. Inovações e projeto político-pedagógico: uma relação regulatória ou emancipatória? In: Cad. Cedes Campinas, v. 23, n. 61, p. 267-281, dez., 2003.

Recebido em: julho 2013

Aprovado para publicação em: dezembro 2013 